\title{
GENESIS 1-2 IN ITS LITERARY CONTEXT
}

\author{
Richard S. Hess
}

\section{Introduction}

The purpose of this essay is to observe the place of the creation account in its literary context in Genesis 1-11. In doing so the argument will examine the dual nature of the account and its designation as one of the תisis. It will then proceed to observe the remaining תițis in Genesis 1-11 and to note the similarities which the creation account itself shares with them in both form and purpose. Finally, some observations will be made as to the implications of this for the literary structure of the first eleven chapters of Genesis.

The dual nature of the creation account has long been noted. It has been one of the axioms of traditional source criticism that the two narratives of Genesis 1 and 2 reflect two distinct sources, the first narrative being representative of the Priestly source and the second of the Yahwist source. ${ }^{1}$ In addition to the difference in the names for God, the argument has proceeded on the assumption that doublets in Genesis lead one to expect origins in two separate sources. More recently, literary studies have been undertaken to argue that, whatever the origins of the creation accounts in these chapters, they serve as a cohesive unit in their present juxtaposition in the Biblical text. ${ }^{2}$ Thus the chapters are not merely the result of careless or unsystematic editing, but may reflect a conscious literary purpose. In addition, we may observe the tendency to find double creation accounts elsewhere in the Ancient Near

\footnotetext{
${ }^{1}$ See, for example, J. Wellhausen, Prolegomena to the History of Ancient Israel (Gloucester, Mass., Peter Smith Reprint, 1973) 297-308; J. A. Soggin, Introduction to the Old Testament (trans. J. Bowden; London, SCM ${ }^{3} 1989$ ) 94-96; B. Vawter, On Genesis: A New Reading (Garden City, New York, Doubleday 1977) 24-25. This distinction often carried forward into the genealogies so that the line of Cain and most of the Table of Nations (10:8-30) are Yahwist, while the lines of Seth and Shem are Priestly. See C. Westermann, Genesis 1-11: A Commentary (ET London, SPCK 1984) 8-18.

${ }^{2}$ E.g. R. Alter, The Art of Biblical Narrative (New York, Basic Books 1981) 141-147.
} 
East. ${ }^{3}$ Both literary and comparative approaches argue for a different emphasis in each of the accounts, which complement one another and so provide a fuller perspective. The Ancient Near Eastern comparisons suggest a common concern to provide a more specific account of creation in the second narrative.

What may also be observed about this 'creation account doublet' is its correspondence to the genealogical doublets of Genesis 4-5 and 10-11. In both cases we find two genealogies juxtaposed to one another. In both cases these genealogies are also designated as תiדisis. 4 In fact, these two doublets of genealogies possess several common features in both form and content, features which are relevant for comparison with the creation accounts of Genesis 1-2. In order to appreciate the similarity of Genesis 1-2 in comparison with the genealogical doublets, we will consider some of the common features of the latter in terms of form, content, and purpose.

\section{The Genealogical Doublets of Genesis 4-5 and 10-11}

1. Both use the expression nithis and include this expression at a point between the two genealogies. This has given rise to speculation as to whether the expression refers to the material which precedes or that which follows it. 5 Important for our purposes is the way in which the expression acts as a link

\footnotetext{
${ }^{3}$ So I. M. Kikawada, "The Double Creation of Mankind in Enki and Ninmah, Atrahasis I 1-351, and Genesis 1-2', Iraq 45 (1983) 43-45.

$45: 1 ; 10: 1 ; 11: 10,27$. Note that there is no $n+1$ the beginning of the line of Cain; although the verb 7 appears in 4:17, a verb which may be related to the mitrin expression. On the meaning and usage of this term see the comment and bibliography in my 'The Genealogies of Genesis 1-11 and Comparative Literature,' Bib 70 (1989) 241-54 [249 n. 25].

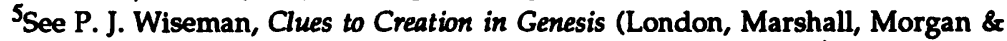
Scott 1979) 34-45, 143-52, for an argument which compares the nitipin expressions to cuneiform colophons and thus assigns them to the preceding section in the Biblical text. U. Cassuto, A Commentary on the Book of Genesis: Part One, From Adam to Noah: A Commentary on Genesis I-VI 8 (ET Jerusalem, Magnes 1961) 96-100, reaches a similar conclusion for Genesis 2:4, but also observes the connection which the expression makes with the text which follows. For the connection of the expression with what follows see F. M. Cross, Canaanite Myth and Hebrew Epic: Essays in the History of the Religion of Israel (Cambridge, Mass., Harvard University Press, 1973) 302-4, who finds in 2:4a evidence of P's use of the expression as a restructuring device superimposed on the JE narrative; G. J. Wenham, Genesis 1-15 Word Biblical Commentary (Waco, Texas, Word $1987) 49$.
} 
between the two genealogies, signifying the end of one and the preparation for the next genealogy to begin. Note that the use of this term in 11:27 does not divide the genealogy of Shem. Instead, it denotes the junction of the first part of the book of Genesis and the story of Abram which follows. ${ }^{6}$

2. Both include at least two sets of linear genealogies which progress for several generations. ${ }^{7}$ It is true that all the genealogies segment ${ }^{8}$ at some point, but this does not change the fact that the texts are concerned to distinguish successive generations in every case.

3. The generations in every case are portrayed as a direct descent related by father and son. This is given in a fashion wherein each genealogy possesses a formula distinct from the others. ${ }^{9}$ This is true in spite of the occasional interruption of glosses and notes which relate to a person or persons of that generation. It is true even of Genesis 10 where, despite the great segmentation, a regular expression, '(And) the sons of $\mathrm{PN}_{1}$ were $\mathrm{PN}_{2} \ldots \mathrm{PN}_{\mathbf{X}}$ ', appears. ${ }^{10}$ However, in both cases of doublets the formula of the first genealogy is brief in comparison to that of the second. ${ }^{11}$

\footnotetext{
6. J. Wenham, Genesis 1-15, 256.

7t is customary to assign the lists of Genesis 4:17-24 and 5:1-32 to J and E respectively, but to find their ultimate origins in a common source, based upon the similarity of names. See J. M. Miller, The Descendants of Cain: Notes on Genesis 4', ZAW 86 (1974) 164-74 [164, 172-3]; J. C. VanderKam, Enoch and the Growth of an Apocalyptic Tradition CBQ Monograph Series 16 (Washington, Catholic Biblical Association of America, 1984) 24-6. However, this is not the only possible explanation. In Mesopotamia the tradition of sages or apkallu whose names sometimes correspond to the kings they served suggests that the lines of Genesis 4 and 5 may also preserve two separate though related traditions. See W. W. Hallo, 'Antediluvian Cities', JCS 23 (1970) 57-67 [63-4]; D. T. Bryan, 'A Reevaluation of Gen 4 and 5 in Light of Recent Studies in Genealogical Fluidity', ZAW 99 (1987) 180-8 [183]; R. S. Hess, 'Genealogies', 247.

${ }^{8}$ On genealogical segmentation, see R. R. Wilson, Genealogy and History in the Biblical World Yale Near Eastern Researches 7 (New Haven and London, Yale University Press, 1977$) 9$.

9Hess, 'Genealogies' 242-4.

${ }^{10}$ This formula is traditionally understood as comprising the $P$ sections of the Table of Nations (G. J. Wenham, Genesis 1-15, 214).

${ }^{11}$ Hess, Genealogies 242-4. The formulae for the genealogies of Seth (Genesis 5) and Shem (Genesis 11) are similar, though that of Shem omits the final phrase.
} 
4. The forms and lengths of each of the genealogical doublets are not parallel, but include variation. Thus in Genesis 4-5 the first genealogy segments after two verses listing five generations. The genealogy of Seth goes on to list nine generations. The same is true of Genesis 10-11. There the line of Shem in Genesis 10 stops halfway through, whereas in the genealogy of chapter 11 it continues on for five more generations. In both chapters 4 and 10 the genealogies provide more discussion of the generations which they describe. This is particularly true as we reach the end of these two genealogies. There is segmentation in Cain's line and the song of Lamech. In the Table of Nations we find greater and greater branching in each generation until we reach the thirteen sons of Joktan.

5. The contents of the doublets are also related. Although an investigation of many of the details lies beyond the scope of this essay, ${ }^{12}$ it should be noted that the first line of ancestry in each doublet includes names whose etymologies and glosses suggest a general category. The second line of ancestry, however, serves to define a specific aspect of this general category. This is clear in Genesis 10 and 11. In the Table of Nations we find figures representing the entirety of the known world. Cities, peoples, and nations are all included. ${ }^{13}$ When we come to the genealogy of chapter 11, we find that scholars have noted the occurrence of place names related to the region of Harran whence came Abram and his family. ${ }^{14}$ Thus the first

\footnotetext{
${ }^{12}$ See R. S. Hess, Personal Names in Genesis 1-11, forthcoming.

${ }^{13}$ For the diversity and inclusive nature of these lists, see D. J. Wiseman, 'Genesis 10: Some Archaeological Considerations', Journal of the Transactions of the Victoria Institute 87 (1955) 14-25; J. Simons, "The Table of Nations (Gen. X): Its General Structure and Meaning', Oudtestamentische Studien 10 (1954) 15484; B. Oded, The Table of Nations (Genesis 10)-A Socio-cultural Approach', ZAW 98 (1986) 14-31.

14J. Skinner, A Critical and Exegetical Commentary on Genesis ICC (Edinburgh, T. \& T. Clark, 21930) 231-2; T. L. Thompson, The Historicity of the Patriarchal Narratives: The Quest for the Historical Abraham BZAW 133 (Berlin and New York, Walter de Gruyter, 1974) 304-6; G. J. Wenham, Genesis 1-15, 251-2; A. Lemaire, 'La haute Mésopotamie et l'origine des bené Jacob', VT 34 (1984) 95101 [96-7]. While accepting these correlations, it is important to remember that the names in Abram's ancestry are also bona fide personal names often attested elsewhere in the Ancient Near East. See N. Schneider, 'Patriarchennamen in zeitgenössischen Keilschrifturkunden', Bib 33 (1952) 516-22; Hess, Personal Names in Genesis 1-11, forthcoming.
} 
genealogy provides a universal geography of the world, while the second genealogy focuses this in a single region, that of Harran in the Northern Euphrates river valleys.

The case is not quite so obvious with Genesis 4 and 5 . Nevertheless, it exists there as well. In the line of Cain we find examples of figures who are related to the origins of various aspects of human culture and civilization. ${ }^{15}$ This is most obvious in terms of the glosses, which describe the building of cities, the 'father of tent dwellers', the 'father of those who play the lyre and pipe', and the metal smith activities of Tubal-Cain. In addition, the etymologies of the names may suggest the category of civilization and culture. Names such as Irad and Enoch may have associations with early cities. Names such as Adah, Zillah, and Naamah may reflect the musical or visual arts.

This theme of culture in Genesis 4 finds a narrowing in Genesis 5. In the line of Seth we find, not human culture and the aspirations of the arts, but the specific concern of the spiritual and the relationship of humanity with its Creator. This is already suggested in 4:26 where, during the generation of Seth's son, Enosh, people began to call upon the name of Yahweh. ${ }^{16}$ It is suggested also by the few glosses which appear in the actual genealogical line of Genesis 5 . This includes the famous gloss on Enoch, who walked with הָגולהָים (vv. 22-24). However this is

${ }^{15}$ For discussion of these glosses, the etymologies of the personal names, and the exact nature of the culture represented here, see the commentaries and articles including J. Gabriel, 'Die Kainitengenealogie: Gn 4, 17-24', Bib 40 (1959) 409-27; R. North, 'The Cain Music', JBL 83 (1964) 373-89 [378-81]; G. Wallis, 'Die Stadt in den Überlieferungen der Genesis', ZAW 78 (1966) 133-48; J. M. Miller, 'The Descendants. Cain: Notes on Genesis 4', ZAW 86 (1974) 16474. P. Klemm, 'Kain und die Kainiten', ZTK 78 (1981) 391-408; J. F. A. Sawyer, 'Cain and Hephaestus. Possible Relics of Metalworking Traditions in Genesis 4', Abr-Nahrain 24 (1986) 155-66.

${ }^{16} \mathrm{On}$ the variety of explanations suggested to explain this verse in light of Exodus 6:3, see W. J. Martin, Stylistic Criteria and the Analysis of the Pentateuch Tyndale Monographs 2 (London, Tyndale, 1955) 18-9; S. Sandmel, 'Genesis 4:26b', HUCA 32 (1961) 19-29; G. J. Wenham, 'The Religion of the Patriarchs', 161-95 in A. R. Millard and D. J. Wiseman (eds.) Essays on the Patriarchal Narratives (Leicester, Inter-Varsity, 1980); R. S. Hess, 'Enosh', Anchor Bible Dictionary, forthcoming. The point here is not affected by the particular explanation used, since, in its present form, all agree that it has to do with a relationship between Enosh (and his generation) and Yahweh. 
interpreted, ${ }^{17}$ it is clearly a spiritual activity which results in Enoch's being 'taken' by God. ${ }^{18}$ Lamech's explanation for the name of his son, Noah, also betrays a spiritual concern (v. 29). It refers to the curse of Yahweh upon the ground after the rebellion of Genesis 3 and expresses the hope that Noah would provide relief from this. ${ }^{19}$

Supporting this theme of spiritual concerns are the etymologies of the names. Here we will note only Enosh and Mahalalel. Enosh is a name whose root is synonymous with Adam. ${ }^{20}$ Both refer to 'person'. Like Adam, Enosh begins a new line and, implicitly, a new hope for humankind. This corresponds to the above mentioned gloss in 4:26. Mahalalel also suggests a spiritual concern. It is a name composed of two

\footnotetext{
${ }^{17}$ On the usage of this expression in the context of Genesis and of the Biblical text, see G. J. Wenham, Genesis 1-15, 127.

${ }^{18}$ For the primary Ancient Near Eastern parallel to this expression, in which an apkallu sage, attached to an antediluvian king who is also seventh in his line, ascends to heaven, see R. Borger, 'Die Beschwörungsserie BTT MESERI und die Himmelfahrt Henochs', JNES 33 (1974) 183-96 [183-7, 192-4]. This note is attached to an apkallu figure, one of the Mesopotamian sages who are often associated with the cultural founders of the line of Cain. For a discussion of the apkallu, see E. Reiner, 'The Etiological Myth of the "Seven Sages"', Or NS 30 (1961) 1-11; and J. C. VanderKam, Enoch and the Growth of an Apocalyptic Tradition, 45-51. For the relationship of the apkallu with the line of Cain, see J. J. Finkelstein, 'The Antediluvian Kings: A University of California Tablet', JCS 17 (1963) 39-51 [50 n. 41]; W. W. Hallo, 'Antediluvian Cities', 63-5; R. S. Hess, The Genealogies of Genesis 1-11 and Comparative Literature', 246. For an extension of this comparison to the incident described in Genesis 6:1-4, see A. Draffkorn Kilmer, 'The Mesopotamian Counterparts of the Biblical NépInm', 39-43 in E. W. Conrad and E. G. Newing (eds.) Perspectives on Language and Text: Essays and Poems in Honor of Francis I. Andersen's Sixtieth Birthday July 28, 1985 (Winona Lake, Indiana, Eisenbrauns, 1987). A relationship between the line of Cain and the Mesopotamian apkallu would enhance the comparison argued here. Rather than mix the figures who represent cultural and spiritual achievements of humanity as in the apkallu tradition of the Ancient Near East, the Biblical text makes a distinction between the general cultural achievements reflected in Cain's line and the specific spiritual one in Seth's genealogy.

${ }^{19}$ On the word play with the name Noah and the relationship of this to the tris root elsewhere in Genesis 1-9, see U. Cassuto, A Commentary on the Book of Genesis: Part One, From Adam to Noah: A Commentary on Genesis I-VI 8 288-9; A. Strus, Nomen-Omen Analecta Biblica 80 (Rome, Biblical Institute Press, 1978) 158-61; G. J. Wenham, Genesis 1-15, 128-9; R. S. Hess, Personal Names in Genesis 1-11: An Onomastic Commentary, forthcoming.

${ }^{20} \mathrm{~F}$. Maass, 'aenos', cols. 373-5 in Band 1 of TWAT (Stuttgart, Berlin, Köln, and Mainz, W. Kohlhammer, 1973).
} 
elements, the first based on the root הלל, 'to praise'. ${ }^{21}$ The second may refer to the generic term for 'God' or it may suggest the divine name El. In either case, we have the praising of a deity as an etymology for Mahalalel. Thus Genesis 5 provides several examples of a spiritual concern among its members. Now this could be understood as an alternative concern to that of the line of Cain. ${ }^{22}$ However, this assumes that the matters of culture represented by Genesis 4 are opposed to the 'spiritual' concerns of Genesis 5; something which is nowhere stated. Instead, it is preferable to find in these texts a general statement of the origins of the arts of living and of civilization (the line of Cain) followed by a specification to that particular 'art' which would concern the offspring of Noah through Shem, that of a spiritual relationship with the divine.

6. Having seen relationships of both form and content in the two doublets, we might also consider their function in the context of Genesis 1-11. In both cases, the doublets serve to connect what precedes with what follows in the text. This takes place clearly in terms of the second genealogy which always begins with those characters which have been found in the narratives preceding the doublet and introduces the main characters of the narratives which follow. In the case of Genesis 5:1-2, Adam is named along with a specific reference to the description of the creation of humanity in $1: 26-27 . .^{23}$

${ }^{21}$ M. Noth, Die israelitischen Personennamen im Rahmen der gemeinsemitischen Namengebung Beiträge zur Wissenschaft vom Alten und Neuen Testament III.10 (Stuttgart, W. Kohlhammer, 1928; reprint Hildesheim and New York, Georg Olms, 1980) 169; J. D. Fowler, Theophoric Personal Names in Ancient Hebrew: A Comparative Study JSOT Supplement Series 49 (Sheffield, JSOT, 1988) 126-7, 136, 342.

${ }^{22}$ An attempt to carry this even farther has been suggested, one in which the murderers in the line of Cain (i.e. Cain and Lamech) intend for that line to contrast with the line of Seth which 'reasserts the created order'. See R. B. Robinson, 'Literary Functions of the Genealogies of Genesis', CBQ 48 (1986) 595608 [600 n. 8]; C. Hauret, 'Réflexions pessimistes et optimistes sur Gen., IV, 1724', 358-65 in J. Coppens, A. Descamps, and E. Massaux (eds.) Sacra Pagina. Miscellanea Biblica Congressus Internationalis Catholici de Re Biblica 1 BETL XII-XIII (Paris, Gabalda; Gembloux, Duculot, 1959). While there is no evidence for the presence of a negative evaluation of the civilized arts in this text, this does not argue the absence of an overall negative evaluation of the line of Cain. See R. S. Hess, Personal Names in Genesis 1-11, forthcoming.

${ }^{23}$ R. B. Robinson, 'Literary Functions of the Genealogies of Genesis', 600-1. For a literary argument which connects this text with what precedes and sees $5: 1 a$ 
Genesis 5 concludes with the introduction of Noah, Shem, Ham, and Japheth, figures who dominate chapters 6-9. Shem is mentioned in Genesis 11:10. Verse 17 introduces the figure of Abram who will dominate the next section of Genesis. The verse introduces his brothers, whose offspring also will play a significant role in what follows.

In contrast with the second genealogy, the first line of descent in each of the doublets begins with characters from the preceding narratives, but does not explicitly introduce characters which appear in the following narratives. Thus Cain's line ends with the immediate family of Lamech. Although some have seen an echo of this line in the incident of Genesis 6:1-4, ${ }^{24}$ there are no names of individuals to connect the latter narrative with the line of Cain. Further, even if this were the case, the connection would serve only to describe how that line came to an end with the judgment of God in the Flood. ${ }^{25}$ In either case, the line ends. The Table of Nations does not meet such a dramatic and destructive end. Rather, we are left to assume that this line continues with the various nations of the world. Indeed, a Sheba (k70 ) mentioned in Genesis 10 as a descendant of Joktan reappears(?) in Genesis 25 as an offspring of Jokshan. However, this is a possible exception to the general pattern which ignores the names in the Table of Nations after Genesis 10, except for those found in the line of Shem through Peleg in chapter 11.

Thus the doublets have a characteristic pattern by which they fit into the narrative context of Genesis 1-11. The first genealogy describes those lines which will not proceed

\footnotetext{
'as both title and topical sentence to the entire Toledoth structure of Genesis', see T. L. Thompson, The Origin Tradition of Ancient Israel. I. The Literary Formation of Genesis and Exodus 1-23 (JSOT Supplement Series 55; Sheffield, JSOT, 1987) 69-70, 73-4. This conclusion rests upon the view that Genesis $1-4$ is best understood as a collection of aetiologies forming a preface to what follows (71-2); a conclusion challenged by the argument here that the literary form of Genesis 1-2 is intended to parallel the genealogical doublets of chapters 4-5 and 10-11. G. von Rad, Genesis: A Commentary (ET London, SCM, ${ }^{3} 1972$ ) 70, also finds here a beginning to a book which was the original basis for the Priestly document.

${ }^{24}$ See A. Draffkorn Kilmer, "The Mesopotamian Counterparts of the Biblical Nepinm'.

${ }^{25}$ See R. S. Hess, 'Nephilim', Anchor Bible Dictionary, forthcoming.
} 
further in the text while the second genealogy continues 'the line of promise' whose named descendants play a role in the succeeding narratives.

\section{Genesis 1-2 and the Genealogical Doublets}

With these aspects of comparison noted in the genealogical doublets, we may now consider the creation doublet of Genesis 1-2.

1. As with the genealogies, the two creation accounts have a statement using the expression תistis between them (2:4).

2. As with the genealogies, there is a linear progression of events in the first creation account. As Genesis 1 is not concerned with the descendants of persons but with the progression of the creation of the universe, there is an alteration in the style of expression. Instead of years and descent, the expression is one of days. This regularity is not true of the creation account in chapter 2.

3. The father-son relationship of the genealogies corresponds to Genesis 1's separation of the light from darkness, of the waters above from those below, and of the dry land from the waters. It also corresponds to the observation that every species reproduces after its kind. There is no intermingling. This sort of ordered reproduction does not appear in Genesis 2's account, nor do we find there the formula of 'evening and morning' followed by the sequential numbering of the days, as we do in Genesis 1.

The pattern of the days in Genesis 1, with its recurrent formula, corresponds to the pattern of the generations in the genealogies. ${ }^{26}$ In neither case is the sequence concerned with

\footnotetext{
${ }^{26} \mathrm{~A}$ similar literary connection has also been observed by J. Scharbert, Der Sinn der Toledot-Formel in der Priesterschrift', 45-56 in H. J. Stoebe, J. J. Stamm, and E. Jenni (eds.) Wort-Gebot-Glaube: Walter Eichrodt zum 80. Geburtstag Abhandlungen zur Theologie des Alten und Neuen Testaments 59 (Zürich, Zwingli, 1970) [53-6]. It is not necessary to connect the succession of days in Genesis 1 with the cosmogonies of Mesopotamian mythology (as C. Westermann, Genesis 1-11: A Commentary, 16). For the distinctives between the two, see G. Hasel, 'The Significance of the Cosmology in Genesis I in Relation to Ancient Near Eastern Parallels', Andrews University Seminary Studies 10 (1972) 1-20; ibid. 'The Polemic Nature of the Genesis Cosmology', EQ 46 (1974) 81-102.
} 
time in terms of some historical measurement. Rather, it is concerned with forward movement, whether in days or in hundreds of years. In Genesis 1 this involves the forward movement of God's creative work. Each day accomplishes something new, bringing about a greater completion of the work of creation. Each day 'begets' the next. As has been observed, the events of the first three days are a necessary background for and correspond to what occurs in the fourth through to the sixth day. Such a forward sequence in the flow of events contrasts with any kind of a mythical or cyclical view of events, wherein the regular rehearsal of the events is necessary to ensure fertility or blessing. Indeed, it points to a perspective in which each day of creation, as each generation of humanity, progresses in the unfolding of a divine plan.

4. In the genealogies we noted how one of the lines of descent was more structured than the other. This is clearly the case with the two creation accounts in Genesis 1-2. There the account of chapter 1 has a structure and regularity which is clearly recognized. On the other hand, Genesis 2:4ff. has no such regularity of form. Of the three niti nis doublets in Genesis $1-11$, the first one, that of Genesis 1-2, has the greatest formal disparity between a structured and an unstructured account.

5. As with the genealogies, we find in Genesis a focusing of content or theme. In chapter 1 , the general account of creation is rehearsed, with little emphasis on any single aspect of the account. In the account of chapter 2 , however, there is a clear emphasis on one particular aspect of creation, the man who is created to work the garden. The whole of the account describes his home, his work, and his companion. It is all centred on the man, planned and created for him. Thus there is a focusing technique between the first two chapters in terms of content, just as there is in the two genealogical doublets.

6. The role of context may also be compared with the genealogical doublets. Of course, nothing precedes the general account of the creation of the world. However, what follows in chapters 3 and 4:1-16 is closely linked with the account of creation in chapter 2 . This fact has long been noted by source critics who ascribe these chapters to the same source. However, we are concerned with a different point, the link between the second account and what follows. What happens in chapter 1? 
This is a self-contained unit which climaxes with the seventh day on which God rests. As with the genealogical doublets there is no explicit continuation of the first account, it concludes in its own fashion and implications about the continuation of the account later in the Bible are not given.

\section{Conclusions}

Thus we find similarities in the creation doublet and in the genealogical doublets of Genesis 1-11. These similarities include areas of form, content, and function. We may suggest that whatever the origins of the material in Genesis, the intent of the writer was to weave together an account of the creation of the world and of humanity using as a major technique doublets of repetitive patterns which serve to focus on a particular theme of the narratives and to provide the major means of moving the events forward into the history of a world known to the early readers of the text.

Such a technique suggests a distinct literary form to the first eleven chapters of Genesis. That this form is distinct has been suggested by the statistical analyses of style which have been undertaken. ${ }^{27}$ That it is a natural division in the contents of Genesis has been noticed. Indeed, the two parts of the book which are joined at the end of chapter 11 are themselves a doublet whose content begins with a more general account of the events touching upon the entire world and then proceeds to more specific narratives which concern the background of the nation of Israel.

\footnotetext{
${ }^{27}$ Y. T. Radday, H. Shore, M. A. Pollatschek, and D. Wickmann, Genesis: An Authorship Study in Computer Assisted Statistical Linguistics Analecta Biblica 103 (Rome, Biblical Institute Press, 1985); and the review article by G. J. Wenham, 'Genesis: An Authorship Study and Current Pentateuchal Criticism', JSOT 42 (1988) 3-18.
} 